\title{
Caracterização antibacteriana e fitoquímica de flores de Hibiscus rosa-sinensis L. (mimo-de-vênus) e Hibiscus syriacus L. (hibisco-da-síria)
}

\author{
Antibacterial and phytochemical characterization of flowers of \\ Hibiscus rosa-sinensis L. (treat-of-venus) and Hibiscus syriacus L. (hibiscus-the-syrian)
}

Analú Barbosa da SILVA ${ }^{*}$, José Maria WIEST ${ }^{1}$, Marcelo Pinto PAIM², Giovani GIROLOMETTO².

${ }^{*}$ Endereço para correspondência: ${ }^{1}$ Instituto de Ciência e Tecnologia de Alimentos, Universidade Federal do Rio Grande do Sul, Rua Domience Silva, 61, CEP 91780-630, Porto Alegre, RS, Brasil. E-mail: absnutri@hotmail.com

${ }^{2}$ Programa de Pós Graduação em Ciências Veterinárias (PPGCV/UFRGS).

Recebido: 26.05.2014 - Aceito para publicação: 25.09.2014

\section{RESUMO}

Hibiscus rosa-sinensis e o Hibiscus syriacus são considerados flores comestíveis e estudos demonstram seu potencial antibacteriano frente a diversos micro-organismos. Este trabalho teve por objetivo analisar a Intensidade de Atividade de Inibição (IINIB) e a Inativação Bacteriana (IINAB) in vitro dos extratos alcoólicos das flores dos hibiscos e a relação com os polifenóis e antocianinas revelados. Avaliou-se a ação antibacteriana frente às bactérias de interesse alimentar, Staphylococcus aureus e Salmonella Enteritidis resultando em diferenças significativas entre as médias de IINIB/IINAB, sendo S. aureus a cepa mais resistente para o $H$. syriacus e $S$. Enteritidis a mais sensível em ambos os experimentos. Com relação ao $H$. rosa-sinensis, este foi eficaz para ambas as bactérias. O teor dos compostos fitoquímicos presentes nas plantas constatou que há uma forte correlação positiva com a atividade antibacteriana $(\mathrm{r}=0,88)$, sendo que o $H$. rosa-sinensis obteve poder antibacteriano maior do que o $H$. syriacus, presumindo estar relacionado à maior quantidade de polifenóis e antocianinas detectadas no primeiro. Conclui-se que as plantas estudadas têm poder bactericida e bacteriostático podendo agir contra a contaminação bacteriana. Palavras chave. Hibiscus rosa-sinensis L., Hibiscus syriacus L., atividade antibacteriana, fitoquímicos.

\begin{abstract}
Hibiscus rosa-sinensis Hibiscus syriacus and edible flowers are considered and studies demonstrate the potential antibacterial against various microorganisms. This study aimed to analyze the Inhibition of Activity Intensity (IINIB) and the Bacterial Inactivation (IINAB) in vitro of alcoholic extracts of flowers of hibiscus and the relationship with the revealed polyphenols and anthocyanins. We evaluated the front antibacterial action of food interest bacteria, Staphylococcus aureus and Salmonella Enteritidis resulting in significant differences between the mean IINIB/IINAB, S. aureus being the most resistant microorganism strain to $H$. syriacus and $S$. Enteritidis was the most sensitive bacteria in both experiments. Concerning the H. rosa-sinensis was effective for both bacteria. The content of phytochemicals compounds found in plants there is a strong positive correlation with the antibacterial activity $(\mathrm{r}=0.88)$, and H. rosa-sinensis obtained antibacterial power greater than $H$. syriacus, assuming be related to increased amount of polyphenols and anthocyanins detected at first. We conclude that the plants have bactericidal and bacteriostatic studied power may act against bacterial contamination.
\end{abstract}

Keywords. Hibiscus rosa-sinensis L., Hibiscus syriacus L., antibacterial activity, phytochemicals. 


\section{INTRODUÇÃO}

Desde a antiguidade, as flores vêm sendo utilizadas para fins comestíveis e medicinais de forma muito específica ${ }^{1}$.

Segundo Felippe e Tomasi ${ }^{2}$, ainda hoje poucos dados comprovam a comestibilidade de flores quando relacionada a compostos de interesse nutricional, pois não há tradição do uso destas na alimentação brasileira, além de pouca pesquisa sobre sua toxicidade. Porém, as flores podem ser ingeridas na forma de infusão, geléias, licores, etc, conforme mencionadas em livros que tratam de plantas medicinais ou mesmo de culinária.

As substâncias naturais de origem vegetal tornam o alimento mais atrativo ao consumidor, além de aumentar a vida útil devido à capacidade bacteriostática e bactericida, que retardam a deterioração e a multiplicação de micro-organismos indesejáveis ${ }^{3}$.

A pressão por parte dos consumidores se volta para uma produção maior de alimentos frescos, com conservantes naturais e uma maior garantia de segurança. Em contraponto, alguns alimentos industrializados contendo altos níveis de conservantes sintéticos são utilizados para redução da carga microbiana, podendo acarretar riscos à saúde dos consumidores ${ }^{4}$.

Conforme Lorenzi et $\mathrm{al}^{5}$, os dados botânicos do Hibiscus rosa-sinensis L., popularmente conhecido como mimo-de-vênus ou hibisco-da-china, são de arbusto pouco ramificado ou simples e lenhoso da Ásia Tropical, que chega a medir cerca de 3 a 5 metros de altura e com grande número de variedades e formas cultivadas nestes países. Seu caule é redondo quase aveludado, com pêlos glandulosos; as folhas são pecioladas, lobadas, alternas, densamente pilosas ao longo das nervuras, com granulações estreladas na face superior; as estipulas são agudas, pubescentes; e os pedúnculos são arqueados, arredondados, pubescente-aveludados. As flores são grandes e solitárias, geralmente brancas de manhã e rosas ou vermelhas à tarde formadas no decorrer de quase o ano todo; suas pétalas são ciliadas na margem, com fruto do tipo capsular com cinco lóculos; e a cápsula é aveludada, com pêlos estrelados e glandulíferos. Segundo Lorenzi e Souza ${ }^{6}$, o Hibiscus syriacus L. possui nomes populares de hibisco-da-síria e rosa-de-sharão. Neste estudo foi utilizado o cultivar "Totus Albus", que corresponde a variedade muito elegante de flores de cor branca pura, medindo de 7 a $9 \mathrm{~cm}$ de diâmetro, às vezes com pétalas rendadas no centro. Arbusto lenhoso ereto e ramificado originado da Ásia, que pode medir de 2 a $3 \mathrm{~m}$ de altura e $2 \mathrm{~m}$ de diâmetro, com folhagem ornamental e ramos colunares. Suas folhas são ovaladas com alguns recortes irregulares, alternas, mucilaginosas, brilhantes, tem margens recortadas e coloração verde-escura. As flores podem ser simples ou dobradas e formam-se durante o ano todo, mas mais abundantes na primavera e verão ${ }^{* 1}$.

O cultivo destas duas variedades se dá a pleno sol como planta isolada, em renques como cerca viva, muros e cercas ou em conjuntos; multiplica-se por estacas e alporques no final do inverno ${ }^{7}$.

As pesquisas sobre o poder antibacteriano de Hibiscus rosa-sinensis foram caracterizadas frente a diversos micro-organismos com resultados satisfatórios, desde 1992 por Andrade et $\mathrm{al}^{8}$, Nair et $\mathrm{al}^{9}$, Seyyadnejad ${ }^{10}$ e Ruban e Gajalakshmi ${ }^{11}$.

Em levantamento realizado por Gautam et $\mathrm{al}^{12}$ de espécies vegetais com ação antibacteriana promissora, verificou-se que o extrato aquoso de Hibiscus syriacus demonstrou efetiva atividade antibacteriana contra Mycobacterium tuberculosis.

Os compostos fitoquímicos são sintetizados por plantas e eficazes contra uma ampla variedade de microorganismos, provavelmente devido à capacidade de formar complexos com proteínas solúveis que se ligam à parede celular bacteriana ${ }^{13}$.

O objetivo desse estudo foi avaliar a Intensidade de Atividade de Inibição Bacteriana (IINIB) e de Inativação Bacteriana (IINAB) in vitro de extratos alcoólicos obtidos das flores de Hibiscus rosa-sinensis $\mathrm{L}$. e Hibiscus syriacus L., frente a Salmonella Enteritidis e Staphylococcus aureus, relacionando estes resultados à presença de polifenóis totais e antocianinas.

\section{MATERIAL E MÉTODOS}

O material vegetal utilizado para as análises foi a estrutura reprodutiva dos arbustos de Hibiscus rosa-sinensis L. e Hibiscus syriacus L. "Totus Albus", denominados neste estudo como hibisco vermelho e hibisco branco, respectivamente. As amostras foram coletadas no período de janeiro a julho de 2013, em uma propriedade agroecológica em Porto Alegre/RS (coordenadas $30^{\circ} 14^{\prime} \mathrm{S}$ e $51^{\circ} 06^{\prime} \mathrm{O}$ ) e identificada por semelhança segundo Lorenzi et $\mathrm{al}^{5}$ para o mimo-de-

\footnotetext{
*1 Conteúdo extraído de <http://www.havlis.cz/karta en.php?kytkaid=441> acesso em 16 julho de 2013.
} 
vênus, e por Lorenzi e Souza ${ }^{6}$ para o hibisco-da-síria.

As pesquisas da atividade antibacteriana e fitoquímica foram desenvolvidas no Laboratório de Higiene do Instituto de Ciência e Tecnologia de Alimentos (ICTA), da Universidade Federal do Rio Grande do Sul (UFRGS), Porto Alegre/RS.

\section{Atividade antibacteriana}

Os experimentos foram realizados em extratos obtidos por processo de extração alcoólica (alcoolatura dos componentes in natura) de flores dos hibiscos, na proporção de $400 \mathrm{~g}$ de flores frescas para $1000 \mathrm{~mL}$ de álcool etílico de cereais a $96^{\circ} \mathrm{GL}$ (Farmaquímica ${ }^{\circ}$, Porto Alegre/RS/Brasil), que permaneceram por no mínimo 15 dias em maceração. Após este período, a alcoolatura foi filtrada em papel filtro, e posteriormente submetida à destilação fracionada sob pressão reduzida em rotaevaporador, desprezando-se a porção alcoólica, para a obtenção do extrato vegetal ${ }^{14}$. Nos extratos obtidos de Hibiscus rosa-sinensis L. trabalhou-se com as concentrações de 50, 25 e 12,5\% e para as flores de Hibiscus syriacus L. “Totus Albus", somente na concentração de $50 \%$.

Foram desafiadas duas cepas-padrão de bactérias, sendo uma Gram-positiva Staphylococcus aureus (ATCC 25923) e uma Gram-negativa Salmonella Enteritidis (ATCC 11076), mantidas na bacterioteca do Laboratório de Higiene (ICTA/UFRGS) em ágar nutriente $\left(\right.$ ACUMEDIA $\left.^{\oplus}\right)$, tendo sido reativadas em caldo infusão de cérebro e coração (BHI - Brain Heart Infusion Broth, Himedia ${ }^{\oplus}$, Índia) incubado a $37^{\circ} \mathrm{C}$ por 24 horas, até atingir no mínimo $1,0 \times 10^{8} \mathrm{UFC} / \mathrm{mL}$. O inoculo foi preparado, por diluição decimal seriada, em solução salina peptonada $1 \%$ tamponada (HIMEDIA ${ }^{\oplus}$ ), de $10^{-1}$ a $10^{-8}: 1$ $\mathrm{mL}$ do inoculo foi transferid o para tubo contendo $9 \mathrm{~mL}$ da solução salina peptonada $1 \%$ tamponada (diluição $10^{-1}$ ); $1 \mathrm{~mL}$ desta diluição foi transferida para novo tubo contendo $9 \mathrm{~mL}$ da solução salina peptonada $1 \%$ tamponada (diluição $10^{-2}$ ) e assim sucessivamente até a diluição $10^{-8}$. O controle do inoculo foi realizado pela técnica de semeadura de $0,1 \mathrm{~mL}$ das diluições $10^{-6}$ e $10^{-7}$, em placas de Petri contendo ágar nutriente para contagem de colônias, seguido de incubação a $37^{\circ} \mathrm{C}$ por $24 \mathrm{~h}$. Para o estudo, somente foram utilizados inóculos que apresentaram população $\geq 1,0 \times 10^{8} \mathrm{UFC} / \mathrm{mL}$, sendo que a atividade antibacteriana dos extratos alcoólicos foi realizada segundo a técnica biométrica adaptada de Cavalli-Sforza ${ }^{15}$.

Utilizou-se a partir de dados do Teste de Diluição segundo DVG ${ }^{16}$, com base na técnica de sistema de tubos múltiplos modificada por Avancini ${ }^{17}$ e revisada por Souza e Wiest ${ }^{18}$; Avancini e Wiest ${ }^{19}$; Maciel et $\mathrm{al}^{20} \mathrm{e}^{\text {Cardoso }}{ }^{21}$, neste último a confirmação para o confrontamento dos extratos com 8 diluições seriais logarítmicas $\left(10^{-1} \mathrm{a}\right.$ $10^{-8} \mathrm{UFC} / \mathrm{mL}$ ) dos diferentes inóculos bacterianos. Os tubos de ensaio foram dispostos em duas linhas para cada bactéria. Na primeira linha (Sem Desinibidores), os tubos continham $1 \mathrm{~mL}$ da diluição do inóculo bacteriano, $4,5 \mathrm{~mL}$ de meio de cultura $\mathrm{BHI}$ duplamente concentrado e $4,5 \mathrm{~mL}$ do extrato vegetal. A segunda série (Com Desinibidores), os tubos continham os mesmos itens, porém acrescidos dos desinibidores bacterianos lecitina de soja (Delaware ${ }^{\oplus}$, Porto Alegre/RS/Brasil), Tween 80 (Synth ${ }^{\oplus}$, Diadema/SP/Brasil) e L-histidina (Synth' ${ }^{\odot}$, Diadema/SP/Brasil), nas porcentagens de $0,6 \%, 6 \%$ e $0,2 \%$, respectivamente. Os tubos foram incubados a $37{ }^{\circ} \mathrm{C}$ por 24 horas e após esse período uma alçada de cada tubo foi semeada em ágar nutriente colocado em incubação aeróbia por 24, 48, 72 e 144 horas a fim de se verificar a presença de crescimento bacteriano.

A avaliação da atividade antibacteriana dos extratos alcoólicos foram interpretados como Intensidade de Atividade de Inibição Bacteriana (IINIB) e Intensidade de Atividade de Inativação Bacteriana (IINAB), representadas por variáveis ordinais arbitrárias de 9 a 0 , sendo que o valor de 9 representou a atividade máxima e 0 , a não atividade, conforme demonstrado no Quadro 1.

Quadro 1. Representação dos valores ordinais arbitrários de intensidade de atividade atribuídos às variáveis de Intensidade de Atividade de Inibição Bacteriana/bacteriostasia (IINIB) e Intensidade de Atividade de Inativação Bacteriana/bactericidia (IINAB), e suas correspondentes diluições e doses infectantes nos inóculos

\begin{tabular}{|c|c|c|c|c|c|c|c|c|c|c|}
\hline 9 & 8 & 7 & 6 & 5 & 4 & 3 & 2 & 1 & 0 & Variáveis ordinárias de intensidade de atividade \\
\hline $10^{-1}$ & $10^{-2}$ & $10^{-3}$ & $10^{-4}$ & $10^{-5}$ & $10^{-6}$ & $10^{-7}$ & $10^{-8}$ & $10^{-9}$ & n.a & UFC/mL - diluições de inoculo inibidas ou inativadas \\
\hline $10^{8}$ & $10^{7}$ & $10^{6}$ & $10^{5}$ & $10^{4}$ & $10^{3}$ & $10^{2}$ & $10^{1}$ & 1 & n.a & UFC/mL - doses infectantes inibidas ou inativadas \\
\hline
\end{tabular}




\section{Análise fitoquímica}

A análise fitoquímica foi realizada em triplicata, utilizando as flores frescas, segundo metodologias específicas. A determinação dos níveis de polifenóis totais foi realizada pelo método Folin-Ciocalteu ${ }^{22}$ e a curva padrão foi produzida com soluções de ácido gálico nas concentrações de $0,25,50,75,100,125$ e $150 \mu \mathrm{g} / \mathrm{mL}$. As leituras foram realizadas em espectrofotômetro (UV Mini 1240, Shimadzu ${ }^{\oplus}$, Japan) a $750 \mathrm{~nm}$. Os resultados foram expressos em miligramas ( $\mathrm{mg}$ ) de equivalentes de ácido gálico (GAE) por $100 \mathrm{~g}$ de flor fresca dos hibiscos. As antocianinas totais foram determinadas pelo método de $\mathrm{pH}$ diferencial, conforme descrito por Giusti e Wrolstad $^{23}$. Foram feitas as medidas de absorbâncias em espectrofotômetro em $540 \mathrm{~nm}$ para pH 1 e $700 \mathrm{~nm}$ para $\mathrm{pH} 4,5$. O teor de pigmentos foi calculado considerando a absortividade molar e os resultados expressos como miligramas (mg) de cianidina 3-glicosídeo/100 g de amostra.

\section{Análise estatística}

Para a avaliação da atividade antibacteriana, foram utilizadas a análise descritiva e a análise de variância (ANOVA), com complementação pelo Teste de Tukey $(\mathrm{p}<0,0001)^{24}$. Estabeleceu-se nível de significância de $0,01 \%$ para resultados considerados com diferença significativa entre as médias. Os programas estatísticos utilizados foram o "Statistical Analysis System" (SAS), versão 9.2 e o "Statistical Package For The Social Sciences" (SPSS/PASWSTAT), versão 18.

Para a avaliação fitoquímica, utilizaram-se as médias dos resultados encontrados de três repetições distintas e o desvio padrão, bem como teste-t com nível de significância $(\mathrm{p}<0,05)$.

Calculou-se a correlação de Pearson das análises fitoquímicas em relação com a atividade antibacteriana utilizando o programa Microsoft Office Excel ${ }^{\circledR} 2007$ Windows 7.

\section{RESULTADOS E DISCUSSÃO}

A Tabela 1 apresenta os valores arbitrários obtidos para as diferentes concentrações do extrato do hibisco vermelho, o qual apresentou diferença significativa entre as médias de IINIB e IINAB para as duas bactérias, independente do tempo de exposição. Obtiveram-se

Tabela 1. Intensidade da atividade de inibição bacteriana (IINIB) e intensidade da atividade de inativação bacteriana (IINAB), produzidas pelo extrato de Hibiscus rosa-sinensis L (hibisco vermelho) nas concentrações de 50 \% (A), 25 \% (B) e 12,5 \% (C), média de três repetições independentes, sobre 2 inóculos bacterianos padrões, em até 144 horas de incubação aeróbia à $37^{\circ} \mathrm{C}$

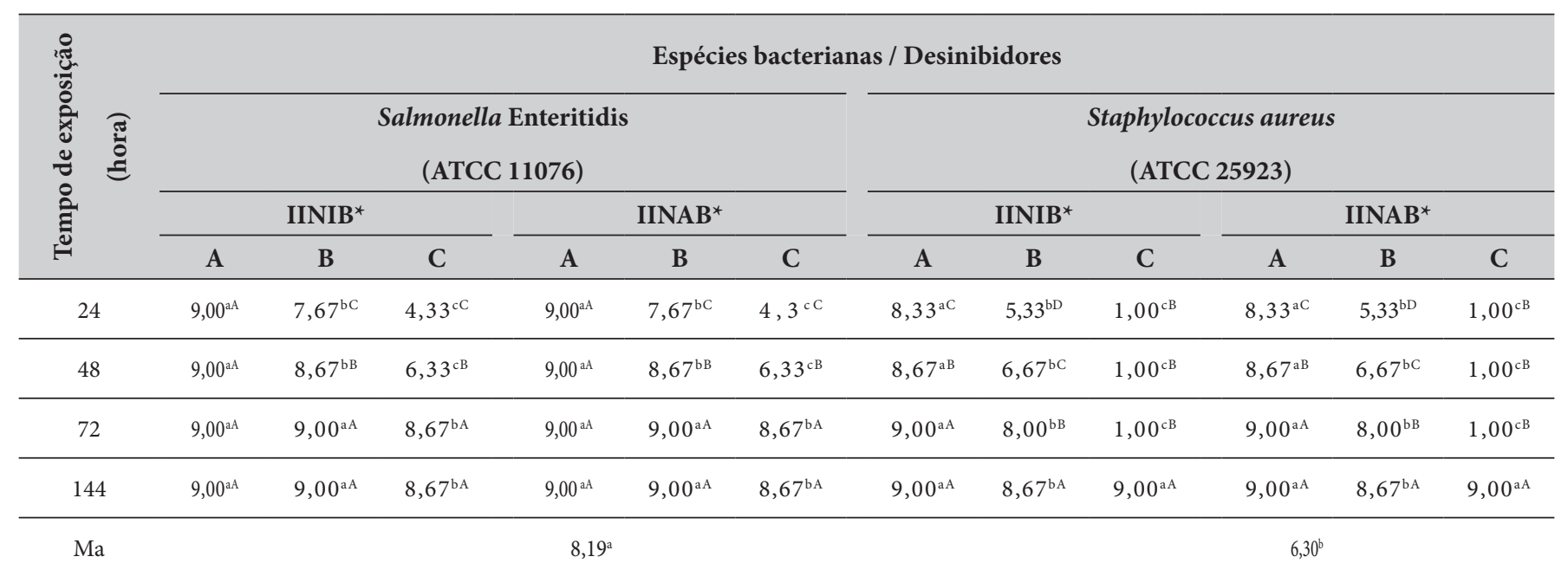

IINIB (sem desinibidor/bacteriostasia); IINAB (com desinibidor/bactericidia). Ma = média aritmética

*9 a $1=$ valores arbitrários que representam a intensidade da atividade antibacteriana (média de três repetições) e $0=$ não atividade

Letras minúsculas diferentes sobescritas $(\mathrm{a}, \mathrm{b}, \mathrm{c})$ na mesma linha para cada inoculo padrão, levando-se em consideração IINIB e IINAB, indicam diferenças significativa, para a análise de variância $($ ANOVA) e teste de Tukey $(\mathrm{p}<0,0001)$

Letras maiúsculas diferentes sobescritas (A, B, C, D), na mesma coluna indicam diferença significativa entre o tempo de exposição para a análise de variância (ANOVA) e teste de Tukey $(\mathrm{p}<0,0001)$ 
as médias aritméticas $(\mathrm{Ma})$ dos valores arbitrários do confrontamento dos extratos nas concentrações de 50, 25 e 12,5 \%, com as bactérias Salmonella Enteritidis, cuja média obtida foi 8,19 e para Staphylococcus aureus de 6,30 , indicando que a dose infectante inibida ou inativada atingiu $10^{7} \mathrm{UFC} / \mathrm{mL}$ e $10^{5} \mathrm{UFC} / \mathrm{mL}$, respectivamente, demonstrando maior sensibilidade da primeira em relação à segunda bactéria.

Constatou-se ainda, que a cepa de $S$. Enteritidis foi inativada/inibida na concentração de $50 \%$ desde as primeiras $24 \mathrm{~h}$ de confrontamento, enquanto que a de S. aureus foi inativada/inibida somente após $72 \mathrm{~h}$ de exposição.
Nota-se que, à medida que as concentrações do extrato diminuem, os valores arbitrários acompanham este decréscimo, sendo menos eficaz a ação frente às bactérias em questão e, conseqüentemente, conforme aumenta o tempo de exposição aumenta a eficácia do extrato.

Estudando a variedade de hibisco branco (Tabela 2), demonstram-se as médias dos valores arbitrários de 8,00 para a cepa de $S$. Enteritidis e 3,00 para S. aureus, em que ocorre sensibilidade da primeira em relação à segunda bactéria devido à menor redução logarítimica de $10^{7}$ para $10^{2} \mathrm{UFC} / \mathrm{mL}$. Assim houve diferença significativa entre as médias, independente do tempo de exposição e IINIB e IINAB entre os dois inóculos bacterianos confrontados ( $\mathrm{p}$ $<0,0001)$ e, o extrato alcoólico do hibisco branco obteve

Tabela 2. Intensidade da atividade de inibição bacteriana (IINIB) e intensidade da atividade de inativação bacteriana (IINAB), produzidas pelo extrato de Hibiscus syriacus L. (hibisco branco) na concentração de 50 \%, média de três repetições independentes, sobre 2 inóculos bacterianos padrões, em até 144 horas de incubação aeróbia à $37^{\circ} \mathrm{C}$

\begin{tabular}{|c|c|c|c|c|}
\hline \multirow{3}{*}{$\begin{array}{c}\text { Tempo de exposição } \\
\text { (hora) }\end{array}$} & \multicolumn{4}{|c|}{ Espécies bacterianas / Desinibidores } \\
\hline & \multicolumn{2}{|c|}{$\begin{array}{l}\text { Salmonella Enteritidis } \\
\text { (ATCC 11076) }\end{array}$} & \multicolumn{2}{|c|}{$\begin{array}{c}\text { Staphylococcus aureus } \\
\text { (ATCC 25923) }\end{array}$} \\
\hline & IINIB & IINAB & IINIB & IINAB \\
\hline 48 & $7,33^{\mathrm{aB}}$ & $7,33^{\mathrm{aB}}$ & $1,00^{\mathrm{bB}}$ & $1,00^{\mathrm{bB}}$ \\
\hline 72 & $9,00^{\mathrm{aA}}$ & $9,00^{\mathrm{aA}}$ & $1,00^{\mathrm{bB}}$ & $1,00^{\mathrm{bB}}$ \\
\hline 144 & $9,00^{\mathrm{aA}}$ & $9,00^{\mathrm{aA}}$ & $9,00^{\mathrm{aA}}$ & $9,00^{\mathrm{aA}}$ \\
\hline
\end{tabular}

IINIB (sem desinibidor/bacteriostasia); IINAB (com desinibidor/bactericidia). Ma = média aritmética

*9 a $1=$ valores arbitrários que representam a intensidade da atividade antibacteriana (média de três repetições) e $0=$ não atividade

Letras minúsculas diferentes sobescritas (a,b) na mesma linha indicam diferenças significativas entre as espécies bacterianas para a análise de variância (ANOVA) e teste de Tukey $(<0,0001)$, independente da presença ou da ausência de desinibidores ou do tempo de exposição

Letras maiúsculas diferentes sobescritas $(A, B, C)$ na mesma coluna indicam diferença significativa entre os valores de IINIB e IINAB pela Análise de Variância (ANOVA) e teste de Tukey $(<0,0001)$, considerando-se as espécies bacterianas

ação máxima antibacteriana em $72 \mathrm{~h}$ para $S$. Enteritidis e em 144 h de exposição frente à $S$. aureus.

Constata-se que as médias dos valores arbitrários para as duas bactérias, tanto para IINIB quanto para IINAB, foram iguais, levando em consideração os tempos de exposição. Contudo os desestressantes/desinibidores incluídos na categoria IINAB garantem esta técnica, não havendo reparação das células bacterianas e evidenciando que as plantas têm poder bactericida, portanto a ação do extrato foi suficiente para inativar as bactérias. Com a mesma metodologia, mas com plantas diferentes, Souza e Wiest $^{18}$ e Girolometto et $\mathrm{al}^{25}$ encontraram resultados superiores para IINIB em relação ao IINAB. Em contraponto, Maciel et $\mathrm{al}^{20}$ predominantemente encontraram valores arbitrários maiores de IINIB e IINAB de Hibiscus sabdariffa L. coletados em dois acessos. 


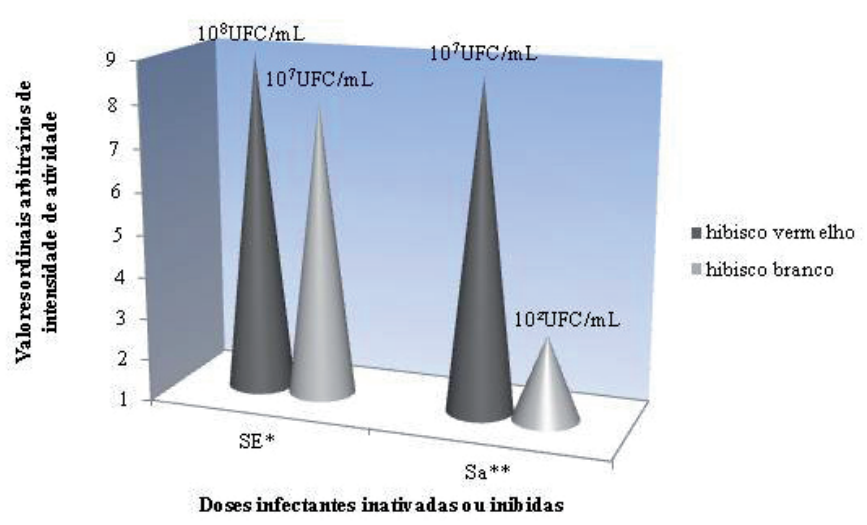

Figura 1. Comparação dos resultados das médias dos valores ordinais arbitrários de intensidade de atividade bacteriana e as doses infectantes inativadas ou inibidas pelos extratos dos hibiscos na concentração de $50 \%$ em confrontamento com as bactérias Salmonella Enteritidis $\left(\mathrm{SE}^{\star}\right)$ e Staphylococcus aureus (SA**).

Analisando a Figura 1, constatou-se que as doses infectantes inativadas ou inibidas das bactérias nos confrontamentos os extratos possuem efeitos bactericida e bacteriostático frente as bactérias de interesse alimentar, em que o $S$. aureus se mostrou a cepa mais resistente, pois foi observado uma redução de apenas 2 ciclos logarítmicos quando comparada com a redução de 7 ciclos logarítmicos de $S$. Enteritidis após a aplicação do extrato de hibisco branco. Já o extrato do hibisco vermelho foi eficaz para ambas as bactérias, atingindo uma dose infectante de inativação ou inibição de $10^{7} \mathrm{e}$ $10^{8} \mathrm{UFC} / \mathrm{mL}$ dos inóculos de $S$. aureus e $S$. Enteritidis, respectivamente.

Perante as doses infectantes inativadas ou inibidas pelos extratos dos dois hibiscos analisados, presume- se que estes poderiam servir como antibacterianos de interesse alimentar, considerando que segundo Forsythe $^{4}$, a dose infecciosa de Salmonella capaz de provocar uma doença de origem alimentar, variando de acordo com a idade e saúde da vítima, com o alimento e com a linhagem, foram $<10^{6}$ células, e que em $S$. aureus encontravam-se na faixa de $10^{5}$ a $10^{8} \mathrm{UFC} / \mathrm{g}$ ou $\mathrm{mL}$.

Comparando os testes do atual trabalho aos resultados da atividade antibacteriana encontrados com outra técnica utilizada por Ruban e Gajalakshmi ${ }^{11}$ que analisaram a atividade antibacteriana in vitro do extrato da flor de Hibiscus rosa-sinensis contra patógenos humanos, foram encontradas respostas semelhantes, demonstrando que a extração de etanol teve maior zona de inibição registrada para Salmonella sp. com outras bactérias como Bacillus subtilis e Escherichia coli. O Hibiscus rosa-sinensis também inibiu o crescimento de S. aureus, $P$. aeruginosas e foi resistente para E. coli ${ }^{10}$, obtendo os mesmos resultados deste estudo para a primeira bactéria. Através de outras técnicas, no trabalho de Nair et al. ${ }^{9}$ a atividade antibacteriana dos extratos aquoso e metanólico de $H$. rosa-sinensis foram testados perante as seis bactérias, resultando em inibição para cinco delas. Concorda-se neste contexto, o que foi verificado com o Hibiscus syriacus, em que os extratos aquosos deste demonstraram atividade antibacteriana considerável em ensaios de diluição em caldo contra o micro-organismo Mycobacterium tuberculosis ${ }^{12}$. Outros gêneros desta espécie de Hibiscus, como o Hibiscus sabdariffa e Hibiscus tiliaceus já demonstraram ação antibacteriana frente aos micro-organismos Micrococcus luteus, Staphylococcus aureus, Pseudomonas aeruginosas, Salmonella choleroesuis e Escherichia coli ${ }^{26,27}$.

Tabela 3. Análise da correlação entre as diferentes espécies de hibisco, da quantidade de polifenóis e antocianinas com a atividade antibacteriana, independente dos fatores tempo de confrontação, espécie bacteriana e da presença ou ausência de dessestressores/desinibidores bacterianos dos extratos alcoólicos

\begin{tabular}{|c|c|c|c|c|}
\hline Espécie vegetal & $\begin{array}{l}\text { Polifenóis totais } \\
(\mathrm{mg} \mathrm{GAE} / \mathbf{1 0 0 g})^{*}\end{array}$ & $\begin{array}{l}\text { Antocianinas } \\
(\mathbf{m g} / \mathbf{1 0 0 g})^{*}\end{array}$ & $\begin{array}{c}\text { Atividade Antibacte- } \\
\text { riana }\end{array}$ & $\begin{array}{c}\text { Coeficiente de correlação } \\
\text { de Pearson }(\mathbf{r})^{* *}\end{array}$ \\
\hline $\begin{array}{c}\text { Hibisco vermelho } \\
\text { (Hibiscus rosa-sinensis L.) }\end{array}$ & $155,85 \pm 0,95$ & $85,71 \pm 0,30$ & 7,25 & \\
\hline $\begin{array}{c}\text { Hibisco branco } \\
\text { (Hibiscus syriacus L.) }\end{array}$ & $84,68 \pm 0,36$ & $10,87 \pm 0,42$ & 5,5 & 0,88 \\
\hline
\end{tabular}

\footnotetext{
*média de 3 repetições distintas; ** correlação de Pearson em que há uma correlação positiva do coeficiente $\mathrm{r}(0<\mathrm{r}<1) ; * * *$ valores na mesma coluna indicam
} diferença significativa para o test-t $(\mathrm{p}<0,05)$ das médias de polifenóis totais e antocianinas entre as duas amostras de planta 
Quanto à relação dos compostos bioativos detectados e a atividade antibacteriana dos dois hibiscos demonstram-se na sequência a Tabela 3 a correlação de Pearson, que resulta na intensidade da relação linear entre as duas variáveis estudadas.

Constata-se que houve diferença significativa entre as duas espécies de planta em relação aos compostos fitoquímicos (Tabela 3). Sobre as médias dos valores arbitrários apresentadas na atividade antibacteriana e as quantidades de bioativos presentes nas flores em questão, demonstra que a relação entre o teor de polifenóis e antocianinas é diretamente proporcional ao poder antibacteriano dos extratos, como relatado por Maciel et $\mathrm{al}^{20}$.

Na correlação de Pearson, indicou-se que há uma forte correlação positiva entre os compostos fitoquímicos e a atividade antibacteriana $(r=0,88)$, ou seja, quanto maior ou menor a quantidade de compostos encontrados nas espécies vegetais, maior ou menor será sua atividade antibacteriana. Assim, o extrato alcoólico do hibisco vermelho obteve poder antibacteriano maior do que o extrato alcoólico do hibisco branco, relacionado à maior quantidade de polifenóis e antocianinas identificados no primeiro.

Para Torres et $\mathrm{al}^{28}$, considerando a riqueza dos constituintes presentes em plantas, igualmente a este estudo com resultado positivo da atividade antimicrobiana dos extratos das espécies vegetais testadas, pode ser devida à presença de compostos polifenólicos detectados, uma vez que estes compostos possuem uma ação inespecífica sobre o micro-organismo, rompendo a parede celular antimicrobiana e inibindo os sistemas enzimáticos para a formação da mesma.

Resultados semelhantes a presente pesquisa foram verificados por Chao e $\mathrm{Yin}^{29}$, em que utilizaram o extrato alcoólico e aquoso de hibisco contra bactérias de interesse alimentar, e concluíram que há uma possível relação entre os compostos fenólicos e o efeito antibacteriano. Na revisão de Ríos e Recio ${ }^{30}$, constatou-se que dos constituintes químicos presentes nas plantas, os compostos fenólicos foram predominantes e as bactérias Gram-positivas são sensíveis a este grupo de substâncias.

\section{CONCLUSÃO}

Os resultados revelaram que os extratos alcoólicos dos dois hibiscos possuem igualmente atividade antibacteriana significativos, apresentando eficácia bactericida, de inativação bacteriana e bacteriostática, portanto de inibição do crescimento bacteriano e, sua relação com os compostos fitoquímicos presentes nas plantas pode influenciar nesta ação.

Sugere-se, contudo, a utilização acerca dos extratos dos hibiscos em questão, como condimentos ou conservantes alimentares, oportunizando alimentos naturais, sensorialmente agradáveis, com vistas à segurança alimentar sustentável. Além da possibilidade destas plantas servirem para sistemas alimentares, prevenindo a contaminação bacteriana e/ou de sua utilização terapêutica.

\section{REFERÊNCIAS}

1. Prata GGB. Compostos bioativos e atividade antioxidante de pétalas de rosas de corte [dissertação de mestrado]. João Pessoa (PB): Universidade Federal da Paraíba; 2009.

2. Felippe GM, Tomasi MC. Entre o jardim e a horta: as flores que vão para a mesa. $2^{a}$ ed. São Paulo: SENAC; 2004.

3. Pereira MC, Vilela GR, Costa LMAS, Silva RF, Fernandes AF, Fonseca EWN et al. Inibição do desenvolvimento fúngico através da utilização de óleos essenciais de condimentos. Ciênc Agrotec.2006; 30(4):731-8.

4. Forsythe SJ. Microbiologia da segurança dos alimentos. $2^{\text {a }}$ ed. Porto Alegre: Artmed Editora; 2013.

5. Lorenzi H, Souza HM, Torres MAV, Bacher LB. Árvores exóticas no Brasil: madeiras, ornamentais e aromáticas. São Paulo: Instituto Plantarum; 2008.

6. Lorenzi H, Souza HM. Plantas Ornamentais no Brasil: arbustivas, herbáceas e trepadeiras. Nova Odessa, SP: Editora Plantarum; 1995.

7. Di Stasi LC, Hiruma-Lima CA. Plantas medicinais na Amazônia e na Mata Atlântica. 2a ed. São Paulo: Editora UNESP; 2002.

8. Andrade FJL et al. Anais do XII Simpósio de Plantas Medicinais do Brasil, 1992.

9. Nair R, Kalariya T, Chanda S. Antibacterial activity of some selected Indian medicinal flora. Turk J Biol.2005;29:41-7.

10. Seyyednejad SM, Koochak H, Darabpour E, Motamedi H. A survey on Hibiscus rosa-sinensis, Alcea rosea L. and Malva neglect Wallr as antibacterial agents. Asian Pac J Trop Med.2010;3(5):351-5.

11. Ruban P, Gajalakshmi K. Atividade antibacteriana in vitro de extrato de flor de Hibiscus rosa-sinensis contra patógenos humanos. Asian Pac J Trop Biomed.2012;2(5):399-403.

12. Gautam R, Saklani A, Jachak SM. Indian medicinal plants as a source of antimycobacterial agents. J Ethnopharmacol.2007;110:200-34.

13. Matias EFF, Santos KKA, Almeida TS, Costa JGM, Coutinho HDM. Atividade antibacteriana in vitro de Croton campestris A., Ocimum gratissimum L. e Cordia verbenacea DC. Rev Bras Bioci.2010:8(3):294-8.

14. Brasil. Farmacopéia Brasileira. Agência Nacional de Vigilância Sanitária. 5ª ed. Brasília: ANVISA; 2010.

15. Cavalli-Sforza L. Biometrie: Grundzüge biologisch-medizinische Statistic (Biometria: fundamentos de estatística viológicamédica). Stuttgart: Gustav Fisher V. 1974. p. 201-4. 
16. DVG (Deutsche Veterinärmedizinische Gesellschaft). Richtlinien zur Prüfung chemischer Desinfektionsmittel für die Veterinärmedizin. In: Schliesser T, Strauch D. Desinfektion in Tierhaltung, Fleisch - und Milchwirtschaft. Stuttgart: Enke V., 455p, 1981.

17. Avancini CAM. Saneamento aplicado em saúde e produção animal: etnografia, triagem da atividade antibacteriana de plantas nativas no sul do Brasil e testes de avaliação do decocto de Hypericum caprifoliatum Cham. E Sochlecht - Hypericaceae (Guttiferae) - ("escadinha", "sinapismo") para uso como desinfetante e antisséptico [tese de doutorado]. Porto Alegre: Faculdade de Veterinária, Universidade Federal do Rio Grande do Sul; 2002.

18. Souza AA, Wiest JM. Atividade antibacteriana de Aloysia gratissima (Gill et Hook) Tronc. (garupá, erva-santa) usada na medicina tradicional no Rio Grande do Sul-Brasil. Rev Bras Plantas Med.2007;9:23-9.

19. Avancini CAM, Wiest JM. Atividade desinfectante do decocto de Hypericum caprifoliatum Cham. E Sochlecht - Hypericaceae (Guttiferae) - ("escadinha", "sinapismo") frente a diferentes doses infectantes de Staphylococcus aureus (agente infeccioso em mastite bovina). Rev Bras Plantas Med.2008;10(1):64-9.

20. Maciel M J, Paim MP, Carvalho HHC, Wiest JM. Avaliação do extrato alcoólico de hibisco (Hibiscus sabdariffa L.) como fator antibacteriano e antioxidante. Rev Inst Adolfo Lutz.2012;71(3):462-70.

21. Cardoso PS. Análise fitoquímica e antibacteriana da planta Hibiscus acetosella WeLw ex Hiern [trabalho de conclusão de curso]. Criciúma (SC): Universidade do Extremo Sul Catarinense; 2011.

22. Moyer RA, Hummer KE, Finn CE, Frei B, Wrolstad RE. Anthocyanins, phenolics, and antioxidants capacity in diverse small fruits: Vaccinium, Rubus, and Ribes. J Agric Food Chem.2002;50:519-25.
23. Giusti MM, Wrolstad RE. Antocyanins: characterizion and measurement with uv-visible sprectroscopy. In: Wrolstad RE (Ed.). Currente protocols in food analytical chemistry. New York: John Wiley \& Sons, 2001. Unit F1.2.1-13.

24. Callegari-Jaques LM. Bioestatística: princípios e aplicações. Porto Alegre: Artmed; 2004. 255p.

25. Girolometto G, Avancini CAM, Carvalho HHC, Wiest JM Atividade Antibacteriana de extratos de erva mate (Ilex paraguariensis A. St.Hill). Rev Bras Plantas Med.2009;11(1):49-55.

26. Wong SK, Lim YY, Chan EWC. Evaluation of Antioxidant, Anti-tyrosinase and Antibacterial Activities of Selected Hibiscus Species. Ethnobot Leaflets.2010;14:781-96.

27. Siqueira CFQ, Cabral DLV, Sobrinho TJSP, Amorim ELC Melo JG, Araujo TAS et al. Levels of Tannins and Flavonoids in Medicinal Plants: Evaluating Bioprospecting Strategies. J Evid Based Complem Altern Med.2012; 7p.

28. Torres EC, Ribeiro A, Soares MA. Abordagem fitoquímica e prospecção do potencial antimicrobiano in vitro das partes aéreas de três espécies vegetais pertencentes à família Lamiaceae. 2008. Disponível em: [http://www.diaadiaeducacao.pr.gov.br/ diaadia/diadia/arquivos/File/conteudo/artigos_teses/Biologia/ Artigos/abordagem-fitoquimica.pdf.] Acessado em: 07/01/2015.

29. Chao CY, Yin MC. Antibacterial Effects of Roselle Calyx Extracts and Protocatechuic Acid in Ground Beef and Apple Juice. Foodborne Pathog Dis.2009;6(2):201-6.

30. Ríos JL, Recio MC. Medicinal plants and antimicrobial activity. J Ethnopharmacol.2005;100:80-4. 